\title{
A regional climate palaeosimulation for Europe in the period 1500-1990 - Part 1: Model validation
}

\author{
J. J. Gómez-Navarro ${ }^{1}$, J. P. Montávez ${ }^{2}$, S. Wagner ${ }^{1}$, and E. Zorita ${ }^{1}$ \\ ${ }^{1}$ Institute for Coastal Research, Helmholtz-Zentrum Geesthacht, Geesthacht, Germany \\ ${ }^{2}$ Department of Physics, Regional Campus of International Excellence "Campus Mare Nostrum", University of Murcia, \\ Murcia, Spain
}

Correspondence to: J. J. Gómez-Navarro (juan.gomez-navarro@hzg.de)

Received: 14 March 2013 - Published in Clim. Past Discuss.: 5 April 2013

Revised: 27 June 2013 - Accepted: 29 June 2013 - Published: 30 July 2013

\begin{abstract}
We present and analyse a high-resolution regional climate palaeosimulation encompassing the European region for the period 1500-1990. We use the regional model MM5 driven at the boundaries by the global model ECHO-G. Both models are forced by reconstructions of three external factors: greenhouse gas concentrations, total solar irradiance and volcanic activity. The simulation skill is assessed in a recent period by comparing the model results with the Climate Research Unit (CRU) database. The results show that although the regional model is tightly driven by the boundary conditions, it is able to improve the reliability of the simulations, narrowing the differences to the observations, especially in areas of complex topography. Additionally, the evolution of the spatial distributions of temperature and precipitation through the last five centuries is analysed, showing that the mean values of temperature reflects the influence of the external forcings. However, contrary to the results obtained under climate change scenario conditions, higher-order momenta of seasonal temperature and precipitation are hardly affected by changes in the external forcings.
\end{abstract}

\section{Introduction}

The rise of global temperature in response to an increase of atmospheric concentrations of anthropogenic greenhouse gases is currently well understood in terms of simple physical mechanisms. However, the magnitude of future projections of climate change are still burdened with large uncertainties. This is even more pronounced at regional scales, where additional processes and feedbacks may modulate the climate response to external forcings (Christensen et al., 2007).
In particular over extra-tropical regions, the uncertainty is important to consider as high internal climate variability may mask the impact/influence of changes of external climate forcings.

Comparing proxy-based climate reconstructions and climate simulations is proposed as a means to reduce the spread in the uncertainties of climate sensitivity (González-Rouco et al., 2009; Schmidt et al., 2013, among others). Such a comparison can furthermore provide useful information about the amplitude of externally unforced climate variations, the processes involved therein and about the skill of climate models in simulating regional climate changes. The latter goal seems particularly important because the estimation of climate change impacts and possible adaptation measures depend on the level of certainty that can be placed on simulated regional climate change projections. However, one important remaining factor refers to the discrimination and quantification of different sources of error, ranging from uncertainties in external forcings to sensitivity and physical parameterizations of global and regional climate models.

Direct comparison between individual proxy records and simulations is hampered by the limited resolution of global climate models (GCM), presently about $200-300 \mathrm{~km}$ at midlatitudes. For GCMs used in palaeoclimatological studies, this resolution might be up to $400 \mathrm{~km}$. Regional characteristics related to a detailed representation of topography and coastlines might cause deviations between simulations and proxy series, which would not be per se indicative of a serious intrinsic deficiency of the GCM. Although computationally expensive, regional climate models (RCM) are a useful tool to better simulate regional climate changes. They only simulate a limited area domain, driven at its boundaries by 
the output of global models. This allows implementing spatial horizontal resolutions of about 20 to $50 \mathrm{~km}$. The higher resolution, together with more realistic parameterizations at local scales, allows RCMs to simulate more realistically the local mechanisms responsible for regional climates that can be important to interpret a particular proxy record.

In this study we focus on the evolution of the climate of the European region during the last five centuries. This period is subject to an intense analysis based on empirical climate reconstructions (Luterbacher et al., 2004; Casty et al., 2007; Küttel et al., 2010). Those reconstructions are based on a variety of different sources, e.g. related to a very rich network of recorded historical evidence, very long instrumental and early instrumental climate series, tree-rings, lake sediments, etc. and thus offer a suitable basis for comparisons with climate model simulations. Additionally, a few almost 400 hundred year-long instrumental temperature series, such as the central England temperature record, are available. All these sources are combined into gridded reconstructions of monthly (or seasonal for early periods) near-surface air temperature (SAT) and precipitation, which are particularly useful for comparisons with coarse-resolution simulations (Luterbacher et al., 2004; Casty et al., 2007). Although uncertainties in the instrumental and early instrumental records cannot be ignored, particularly in their early part, they are generally more reliable than other indirect indicators of temperature. This is particularly important in situations when disagreements between model simulations and reconstructions purely based on natural proxies cannot be completely resolved.

As previously mentioned, comparisons with reconstructions, as well as the assessment of the role of internal versus externally forced variability at regional scale, requires high-resolution simulations over long periods of time, demanding high computational costs. Consequently, only few high-resolution climate simulations are available over this area. Gómez-Navarro et al. (2011) studied the evolution of the climate through a millennial simulation over the Iberian Peninsula, by comparing the simulation output with available climate reconstructions, and used different simulations sharing the same external forcings to analyse the role of internal variability (Gómez-Navarro et al., 2012). Schimanke et al. (2012) employed a regional climate model and a regional ocean model to study the evolution of climate in the Baltic Sea region during the last millennium and perform sensibility studies.

The added value of RCM is normally established by estimating the degree of agreement between the model results and a set of observations. This approach can be misleading to model developers because the mismatch between simulations and observations includes different types of errors. A comparison does not allow for the establishment of whether the added value provided by the regional model is just due to the higher resolution, or based on improvements within the model in the simulation of the underlying physical processes
(Kanamitsu and DeHann, 2011). However, from the point of view of the final users of climate simulations, this distinction might be less important. The output of global and regional models is viewed as a source of potentially useful data, regardless of the real causes of the model deficiencies. This is the point of view that we adopt in this manuscript.

Another aspect of the added value is the importance of its spatial distribution. Kanamitsu and DeHann (2011) showed that the added value is not spatially homogeneous, but rather tends to be more noticeable over or close to areas of complex orography. Thus, the geographical distribution of skill can be a piece of useful information for the user. This issue is demonstrated in many other regional studies. For instance, Prömmel et al. (2009) illustrated the added value of a highresolution hindcast simulation over the Alpine region with respect to the driving data, and showed how it is specially noticeable over complex areas. Thus, in this study we identify areas where the added value of the RCM is more noticeable, as well as where the use of coarse-resolution climate simulations, without the use of any downscaling technique, is a reasonable choice.

The objective of the present study is to identify the added value of a high-resolution climate palaeosimulations for $\mathrm{Eu}-$ rope with respect to state-of-the-art GCMs, as well as to show the skill and drawbacks of the MM5-ECHO-G setup to reproduce a realistic climate for the last centuries. The comparison between the model simulation with currently available climate reconstructions for Europe will be performed in a follow-up paper. After presenting the technical details of the climate simulations along with a short summary of the observational data set employed as reference in this study, we present in Sect. 3 a validation of the climate simulations for the present-day climate. Section 4 analyses the evolution of probability distribution functions in different key periods of time within the simulation. Finally, the paper closes with the conclusions and an outlook.

\section{Data and simulations details}

For this study a regional simulation of the European climate is performed for the period 1501-1990 AD. The RCM employed is a climate version of the meteorological model MM5 driven at its domain boundaries by the GCM ECHO-G (the model configuration is hereafter referred to as MM5ECHO-G). Both models are driven by estimates of three external forcing types illustrated in Fig. 1: greenhouse gas (GHGs) concentrations in the atmosphere, long-term variations in total solar irradiance (TSI), and the global radiative forcing of stratospheric volcanic aerosols. To avoid physical inconsistencies both models, GCM and RCM, were driven by identical external forcings. A full description of the global simulation and the external forcings is found in Zorita et al. (2004); Gómez-Navarro et al. (2011, and references herein). 


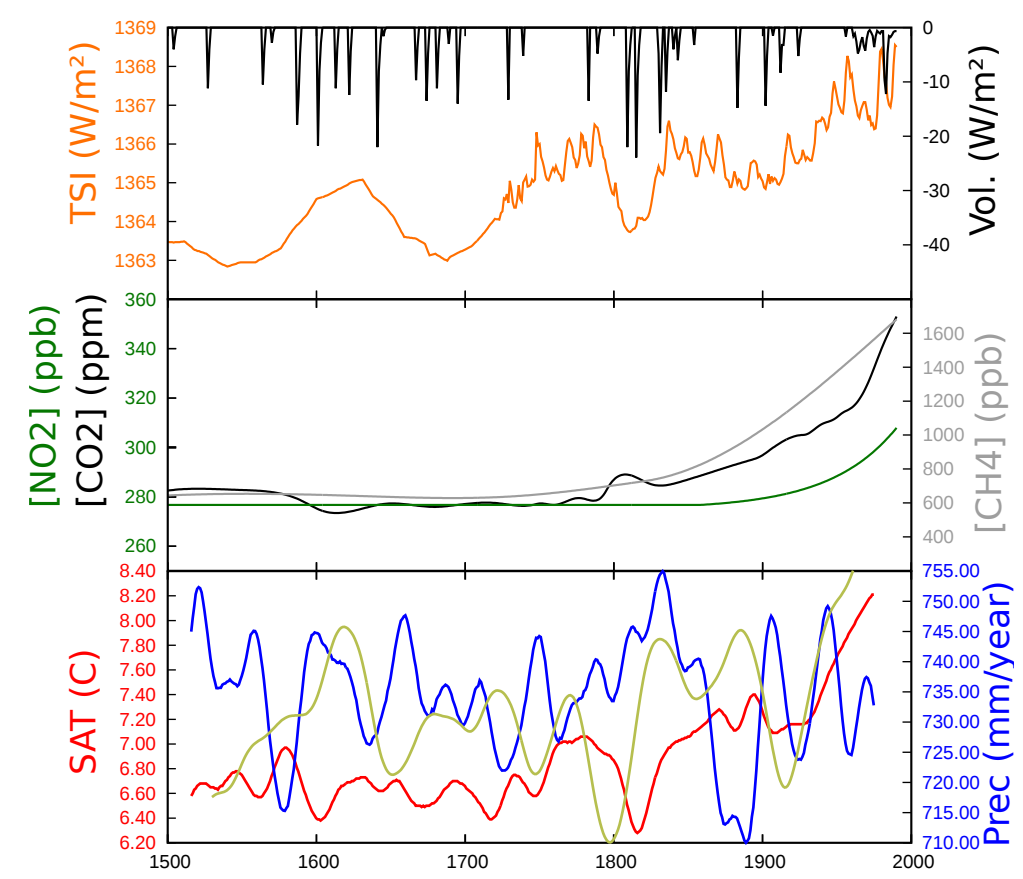

Fig. 1. Three sources of external forcings implemented in the simulation and evolution of spatially averaged SAT (red) and precipitation (blue) over the whole domain in the regional simulation. The NAO index is also represented by dark yellow in arbitrary units. The original annual series in the bottom panel are high-frequency filtered using a Hamming window of 30 time steps. Zorita et al. (2004) described with further details these forcings.

The ECHO-G global model driving the RCM consists of the spectral atmospheric model ECHAM4 coupled to the ocean model HOPE-G (Legutke and Voss, 1999). The model ECHAM4 is used with a horizontal resolution T30 $\left(\sim 3.75^{\circ} \times 3.75^{\circ}\right)$ and 19 vertical levels. The horizontal resolution of the ocean model is approximately $2.8^{\circ} \times 2.8^{\circ}$, with a grid refinement in the tropical regions for a better representation of ENSO and related phenomena and 20 vertical levels to allow. A flux adjustment between the atmosphere and ocean submodels, constant in time and with vanishing spatial average, is applied to avoid climate drift.

The RCM used for the present study is the climate version of the Fifth-Generation Pennsylvania-State UniversityNational Center for Atmospheric Research Mesoscale Model (Dudhia, 1993; Grell et al., 1994; Gómez-Navarro et al., 2011; Jerez et al., 2013). Two two-way nested domains are employed in the simulation with a spatial resolution of 135 and $45 \mathrm{~km}$, respectively. Figure 2 depicts the inner domain, with the actual model topography. The present study focuses on this domain. The atmosphere is represented by 24 sigma levels in the vertical, with the top level located at $100 \mathrm{hPa}$. The boundary conditions of the GCM ECHO-G are assimilated into the RCM through a blending area of five grid points at the fringes of the outer domain. These areas are not reliable in general and are excluded from the analysis hereafter.

The configuration of the RCM physics is chosen to minimise the computational cost. This cost criterion is selected because none of the tested configurations provides an optimal performance for different kinds of synoptic events and regions (Jerez et al., 2013). The physical options implemented are as follows: Grell cumulus parametrization (Grell, 1993), Simple Ice for microphysics (Dudhia, 1989), RRTM radiation scheme (Mlawer et al., 1997) and MRF for boundary layer (Hong and Pan, 1996). The Noah Land-Surface model (Chen and Dudhia, 2001a,b) is used, because it simulates more accurately the climate in dry areas, especially in summer (Jerez et al., 2010). Boundary conditions are updated at the boundaries of the RCM every $12 \mathrm{~h}$.

To assess the skill of the MM5-ECHO-G setup in reproducing the climate in a recent past period, we compare the seasonal mean values of SAT and precipitation with the monthly data set developed by the Climate Research Unit (CRU) at the University of East Anglia (Harris et al., 2013). The CRU (dataset version CRU TS3.00) is a gridded product that extends over the global land surface with a spatial resolution of $0.5^{\circ} \times 0.5^{\circ}$ and includes several climatic variables for the period 1901-2005 AD. However, for the comparison purposes in this analysis only temperature and precipitation series up to 1990 are considered. The data is interpolated onto the MM5 grid to provide a better basis for comparison. Due to missing information over oceanic parts in the CRU data set, only land points are considered for the comparison. 


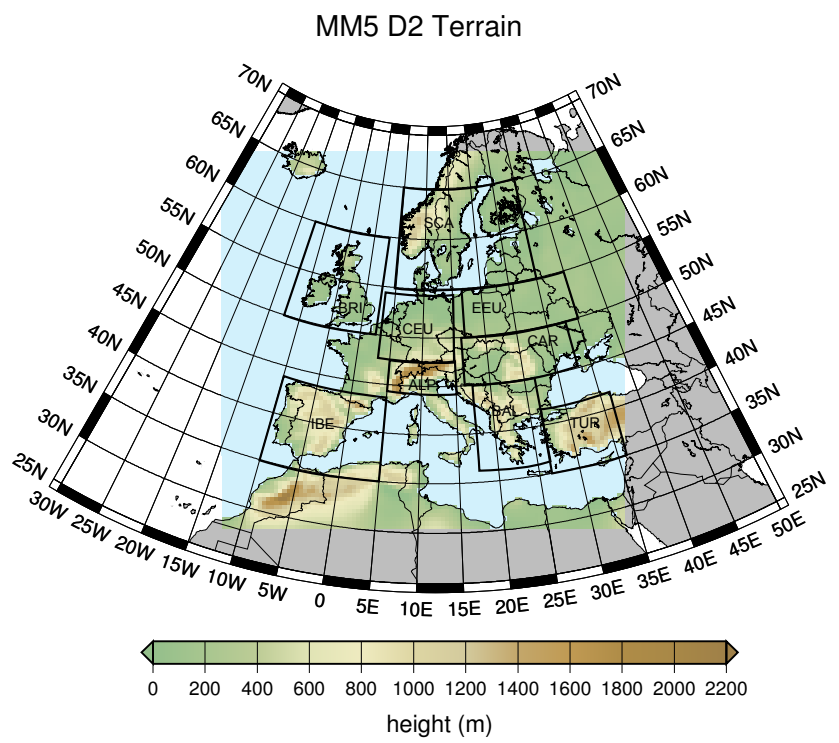

Fig. 2. Topography implemented in the inner domain of the MM5 simulation, with a spatial resolution of $45 \mathrm{~km}$. The mother domain covers a larger area with $135 \mathrm{~km}$ of resolution (not shown). The figure illustrates the 9 subregions, selected according to geographical considerations, used for more detailed analysis hereafter: IBE, Iberian Peninsula; BRI, British Isles; CEU, central Europe; EEU, eastern Europe; SCA, Scandinavian Peninsula and Baltic Sea; CAR, Carpathian Region; BAL, Balkan Peninsula; ALP, Alps; TUR, Turkey. The projection employed in this figure is the same as the one implemented in the RCM, Lambert Conformal, to illustrate as realistically as possible the domain setup. Note however that we use the Mercator projection in the figures hereafter to maximize the available space and facilitate the visualization.

\section{Reproducing the present climate}

The regional model skill of reproducing a realistic climate is assessed to highlight the improvement of the regional climate simulation over the global model, but also to identify possible important deficiencies. Therefore, several climate variables of the simulation are compared with the CRU observational datasets in a reference period. The statistics of the seasonal series of SAT and precipitation are analysed in Sect. 3.1. Additionally, the analysis of Probability Distribution Functions (PDFs) is discussed in Sect. 3.2.

\subsection{Climatologies during 20th century}

A first assessment of the skill of MM5 driven by ECHO-G is performed for the observed climate in the period 19601990 (hereafter referred as the reference period). We specifically focus on seasonal mean values and variability of SAT and precipitation. For this purpose we have used the CRU database (Harris et al., 2013).

The top row in Fig. 3 depicts the time-averaged SAT in winter (left panels) and summer (right panels) for the reference period in CRU. The second and third rows represent the difference between the MM5-ECHO-G setup and ECHO-G alone with respect to CRU. The significance of these differences is tested through a two-tailed $t$ test, as indicated with small black circles in the maps. In winter, the RCM describes the general spatial pattern relatively well, with the coldest areas in the northeastern part of the domain and the warmest in North Africa. Some deviations appear nevertheless more clearly when looking at the difference pattern. It significantly corrects the driving model, strongly reducing the temperature biases in the areas close to the Mediterranean Sea, with an average warm bias of $0.3 \mathrm{~K}$ in the areas south of $45^{\circ} \mathrm{N}$, and few areas with significant differences over the Iberian Peninsula. It is however too warm in northern Europe (the average warm bias is $2.8 \mathrm{~K}$ for the areas north of $45^{\circ} \mathrm{N}$, and it is larger than $5 \mathrm{~K}$ in some areas). This warm bias is opposite to the one reproduced by ECHO-G, which clearly shows a bipolar behaviour with strong significant cold bias in the eastern parts of the domain. This picture is inverted in summer, when the RCM is homogeneously too cold. It simulates the general pattern relatively well (in particular it is able to capture the main mountain systems, which the global model fails to reproduce due to its coarser resolution), but a marked difference in northern and southern Europe is clear. In this season the RCM is too cold, more remarkably in areas near the Mediterranean Sea (the average cold bias over the Iberian Peninsula is $-3.9 \mathrm{~K}$ ). Although significant, these warm/cold biases are within the ranges simulated for the present climate by other state-of-the-art RCMs employed for climate change projections in Europe (Jacob et al., 2007).

Figure 4 depicts similar information as Fig. 3 for precipitation. Wettest areas in winter are near the western coasts and in the main mountain regions, as corresponds to a circulation dominated by the westerly moist flow. Although ECHO-G shows strong dry biases in these areas due to its coarse resolution, MM5 is able to reduce this bias to a large extent. However some caveats are still apparent. In winter there is a clear bipolar behaviour: the RCM overestimates the precipitation in northern Europe, but underestimates it in the Mediterranean area. The same bipolar behaviour, but inverted, is found in summer, although in this case the bias is smaller and in many areas it is not statistically significant. In this season, the largest precipitation coincides with orography (see Fig. 2), and the high resolution of the RCM is able to reproduce this behaviour to a large extent (the spatial correlation between the MM5-ECHO-G setup and observations is 0.71). However, important bias still remain in these areas, especially over the Alps and the Pyrenees. These differences can be attributed to model or observation deficiencies. Note that the $45 \mathrm{~km}$ resolution of the RCM still cannot capture high-resolution orographic features such as valleys, which play an important role in these areas. Regarding the gridded observations, spatial interpolation of observations to create gridded products is especially difficult over mountainous areas, where spatial correlations may be low (Osborn and Hulme, 1997). 


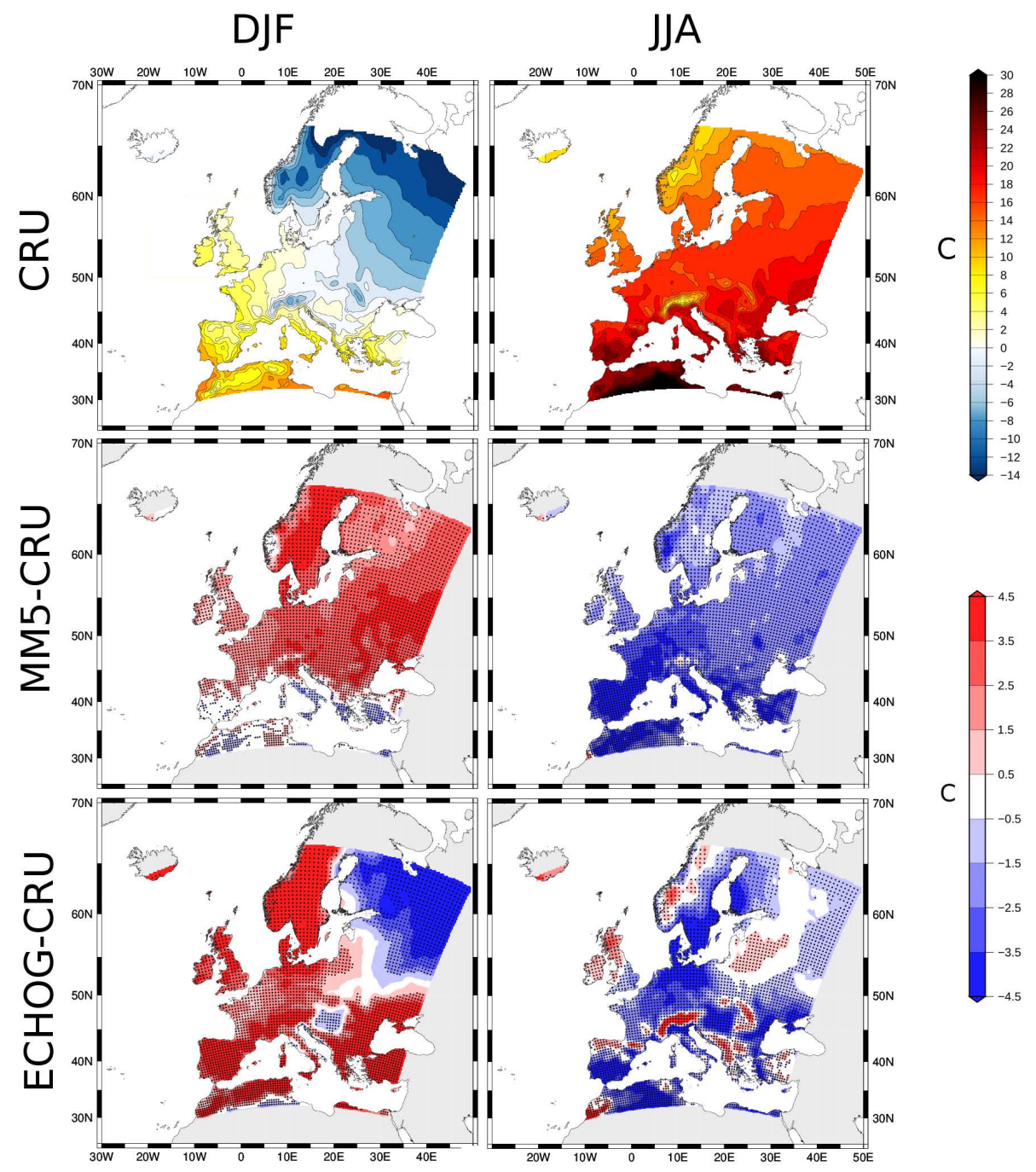

Fig. 3. SAT averaged (in ${ }^{\circ} \mathrm{C}$ ) for the 1960-1990 period in winter (left panels) and summer (right panels) in CRU (top panels), and differences between MM5 driven by ECHO-G (middle panels) and ECHO-G alone (bottom panels) with respect to the former. To perform the calculations, all datasets are spatially interpolated onto the MM5 grid, and only non-ocean grid cells are considered. The significance of the differences is tested through a two-tailed $t$ test at the $95 \%$ confidence level and it is indicated with small black circles in the figure.

To assess further the origin of the RCM biases, the driving simulation is investigated. As shown by Fig. 3, the warm bias in winter is already present in the stand-alone ECHO-G simulation, with the notable difference of a strong cold bias in the most northeastern part of the domain. In ECHO-G the warm bias is even larger near the Mediterranean, pointing to an improvement in this area due to the higher resolution of the RCM. This warm bias in northern Europe seems to be caused by an overestimation of the strength of the zonal circulation, which advects too much warm and moist air from the Atlantic Sea. This overestimation is due to a too intense pressure gradient simulated by ECHO-G, as illustrated by the mean sea level pressure (MSLP) pattern in Fig. 5. The flow associated with this pressure gradient is introduced into the RCM through the boundaries of the domain, causing advection of warm air masses to the biased area in winter. The anomalous flow of warm moist air from the ocean also explains the larger precipitation amounts in this season in northern Europe.

The cold bias in summer is also present in the ECHO-G simulation, with the exception of the main mountain systems. Here, the bias is smaller since the GCM is not able to represent the mountain ranges due to its coarse resolution. The $\mathrm{RCM}$ is still able to reduce the bias over these mountains, but it cannot be completely corrected. Comparing Figs. 3 and 4, the cold bias in summer near the Mediterranean is linked to too wet conditions. A possible explanation may involve a too extensive cloud cover and precipitation in summer, thus reducing the incoming solar radiation and cooling this area relative to the observations. This hypothesis, though plausible, 


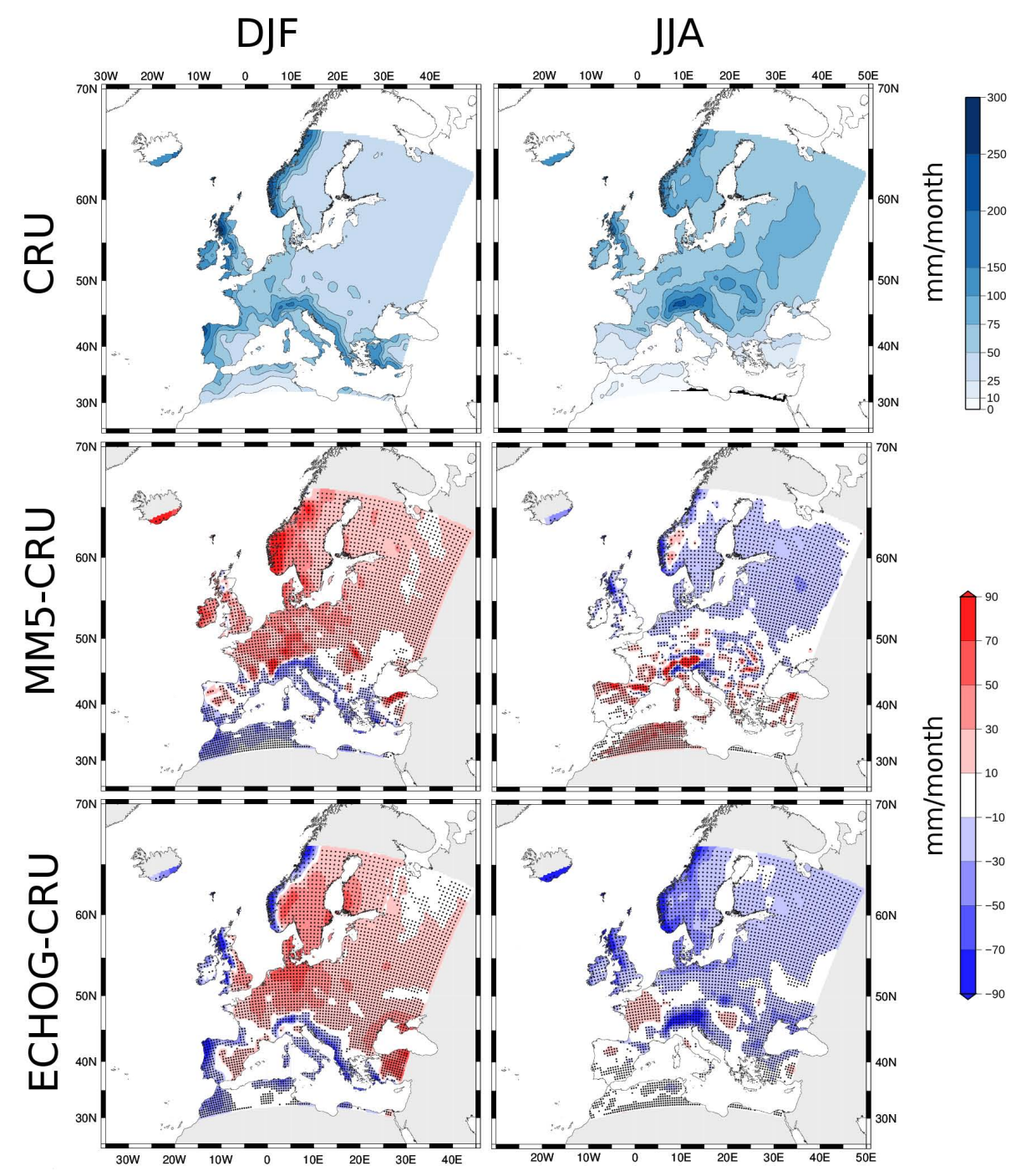

Fig. 4. Precipitation averaged (in mm month ${ }^{-1}$ ) for the $1960-1990$ period in winter (left panels) and summer (right panels) in CRU (top panels), and differences between MM5 driven by ECHO-G (middle panels) and ECHO-G alone (bottom panels) with respect to the former. To perform the calculations, all datasets are spatially interpolated onto the MM5 grid, and only non-ocean grid cells are considered. The significance of the differences is tested through a two-tailed $t$ test at the $95 \%$ confidence level and it is indicated with small black circles in the figure.

is hard to test due to the lack of reliable observations of the cloud fraction over this area for the reference period.

We also evaluate the variability of the RCM and its spatial structure against the observations in the reference period. Figure 6 shows the same information than Fig. 3 but for standard deviation of SAT. As before, the significance of these differences is tested, in this case with a two-tailed $F$ test for the ratio of two variances. In winter, the variability in both the RCM and the observations is larger than in summer, most notably in the northern areas. MM5 underestimates the winter variability in general, although only in some areas, such as central Europe, the simulated variability is up to a third of the observed. Despite this general underestimation of the variability of seasonal SAT series in the model, the spatial structure is very similar (spatial correlation 0.84), with a clear northeastern-southwestern gradient. Similarly, MM5 is generally less variable in summer, with the largest deviations in northeastern Europe, where they become significant. There are two clear areas, in the northwest of the Iberian Peninsula and the west of Scandinavia, where the model overestimates the variability, although it is not statistically significant. Figure 7 depicts the same information for precipitation. Usually, precipitation variability is linearly related to its mean value, and this explains why the ratio patterns in this figure are similar to those of the difference in the mean (Fig. 4). Nevertheless, the pattern is patchy, and no clear pattern of underestimation or overestimation of 

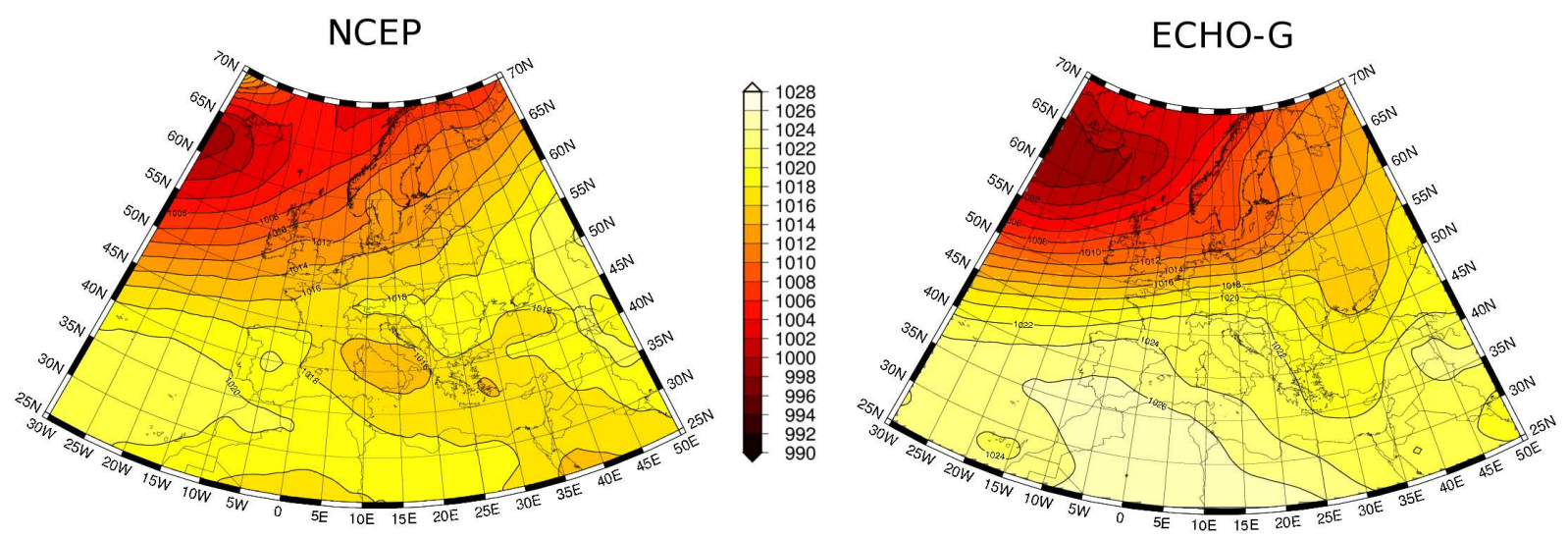

Fig. 5. MSLP in winter in the reference period in the NCEP reanalysis (Kalnay et al., 1996) (left panel) and simulated by ECHO-G (right panels). The units are $\mathrm{hPa}$.

precipitation variability, beyond the aforementioned link between precipitation variability and amount, is identified.

In the next step the simulated and observed long-term trends are analysed. For these statistics we consider a longer period, 1900-1990, which allows for the evaluation of the simulated warming trend during the 20th century and compare it with the observations. Figure 8 represents the SAT trends for winter and summer during this period in CRU (top panels), simulated by the MM5-ECHO-G setup (middle panels) and by ECHO-G alone (bottom panels). Significance of these trends are tested with the non-parametric Mann-Kendall test (assuming that the detrended residuals are independent, which is a reasonable assumption at local scales for interannual series) and indicated with black circles in the figure. The trends in both models are similar, indicating that the long-term variability is tightly prescribed by the driving model. Compared with the observations, both models clearly overestimate the final warming trend, especially in winter and over the northern areas. The CRU database exhibits a negative trend around the Baltic Sea, which is absent in the simulations. Although these trends are not significant due to the large variability in these areas (see Fig. 6), there are two physical explanations for this difference. On the one hand, these simulations (both the global and regional models) do not include the forcing due to anthropogenic tropospheric aerosols. Thus, they do not take into account the increase in aerosol concentrations that would affect the last part of the simulation. This forcing, albeit with large uncertainties, is believed to cause a net cooling (Andreae et al., 2005). On the other hand, a great part of this overestimation of the warming trend in winter can be attributed to the increase of zonal circulation produced by the driving model during this period. This can be clearly seen in the NAO index (Fig. 1). It has to be noted that the long-term evolution of NAO, and thus other related variables such as precipitation, is to a great extent driven by internal variability (Gómez-Navarro et al., 2012; Gómez-Navarro and Zorita, 2013), and thus an agreement between observations and simulations cannot be expected, even if the model were perfect. Similarly, Fig. 9 represents the trends simulated and observed for precipitation during the 20th century. Although the observation pattern is patchy, the RCM exhibits a clear bipolar structure in winter, with larger precipitation in northern Europe and lower in the south. This bipolar structure is again traced back to the intensification of the zonal circulation in the last part of the last century that is not present in the observations.

Summarizing this section, the MM5-ECHO-G setup is able to reproduce many aspects of the present climate in Europe. Some biases compared to the CRU database are found in the reference period, although they are within the range of of other biases simulated by current state-of-the art RCMs employed in climate change projections (Jacob et al., 2007). In particular, winters tend to be too warm and wet, and summers too cold. This underestimation of the annual cycle seems to be related to an overestimation of the zonal flow in the GCM, as well as to an overestimation of the precipitation amount, mostly near the Mediterranean Sea in summer. However, the analysis of the trends during the 20th century shows that the overestimation of zonal circulation is especially noticeable in the last part of the simulation (when the forcings are larger), which is the period employed here as validation. Thus, the size of these biases is expected to be equal or even smaller during the simulated past. Finally, it is important to note that the simulation tends to underestimate the interannual SAT variability compared to observations (see Fig. 6), and this can bear some relevance when comparing the variability of long-term series in the model and in proxy-based reconstructions.

\subsection{Probability distribution functions}

In this section we analyse the probability distribution functions (PDFs) of seasonal series of SAT and precipitation over different areas. We emphasize the added value of the 


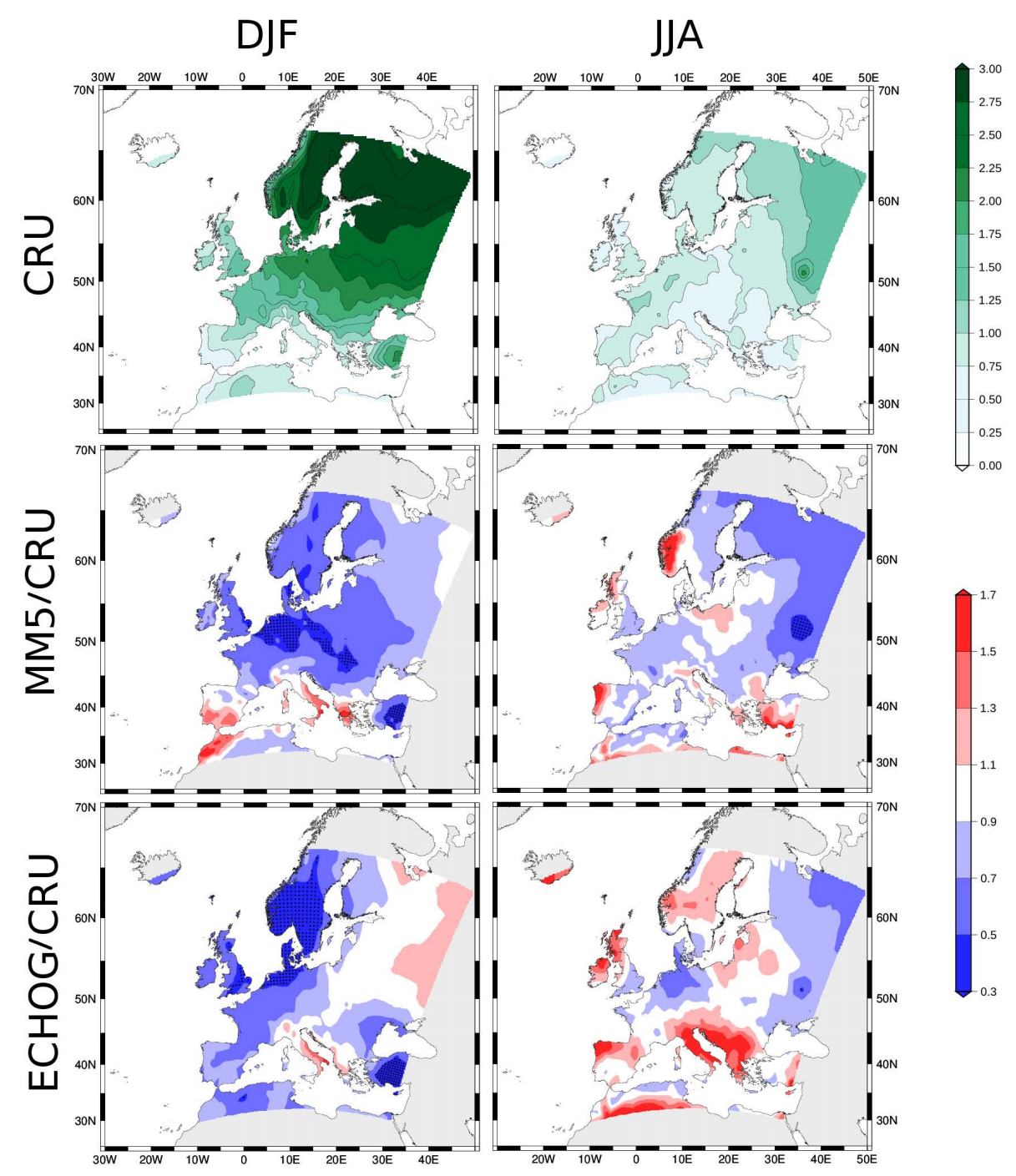

Fig. 6. Standard deviation of seasonal SAT series (in ${ }^{\circ} \mathrm{C}$ ) for the $1960-1990$ period in winter (left panels) and summer (right panels) in CRU (top panels). Panels below show the ratio between MM5 driven by ECHO-G and CRU (middle panels) and ECHO-G alone and CRU (bottom panels). To perform the calculations, all datasets are spatially interpolated onto the MM5 grid, and only non-ocean grid cells are considered. The significance of the ratio is tested through a two-tailed $F$ test at the $95 \%$ confidence level and it is indicated with small black circles in the figure.

regional simulation, as well as identify where it is especially noticeable.

Figure 10 shows the PDFs of the seasonal series of SAT for winter and summer during the 1900-1990 period as simulated by the GCM, the RCM and in the CRU dataset. For this calculation, a longer period is considered to increase the sample size and improve the representativeness of the PDFs. Instead of spatially averaging the variables prior the calculation of the PDFs, we calculate them independently for every grid point, and then average the PDFs for each area. In order to avoid averages over too large areas, which would dilute the added value of the RCM at regional scales, nine areas are selected according to geographical guidelines (shown in Fig. 2). Comparing the MM5 results with the observations (blue and red lines, respectively), it is again apparent that the RCM tends to overestimate winter temperature, especially in central and eastern Europe. The opposite behaviour is found in summer, leading to the underestimation of the annual cycle discussed above. The added value of the regional simulations is illustrated by comparing GCM and RCM results (blue and green lines, respectively). Although the mean temperature in the RCM is largely determined by the driving GCM, in most areas the regional model tends to narrow differences from the observations, especially when the bias is large, as in the Balkan Peninsula in winter or Scandinavia in summer. There are, however, some areas where the change introduced by the RCM is less significant, as in central Europe, where the differences between the global and 


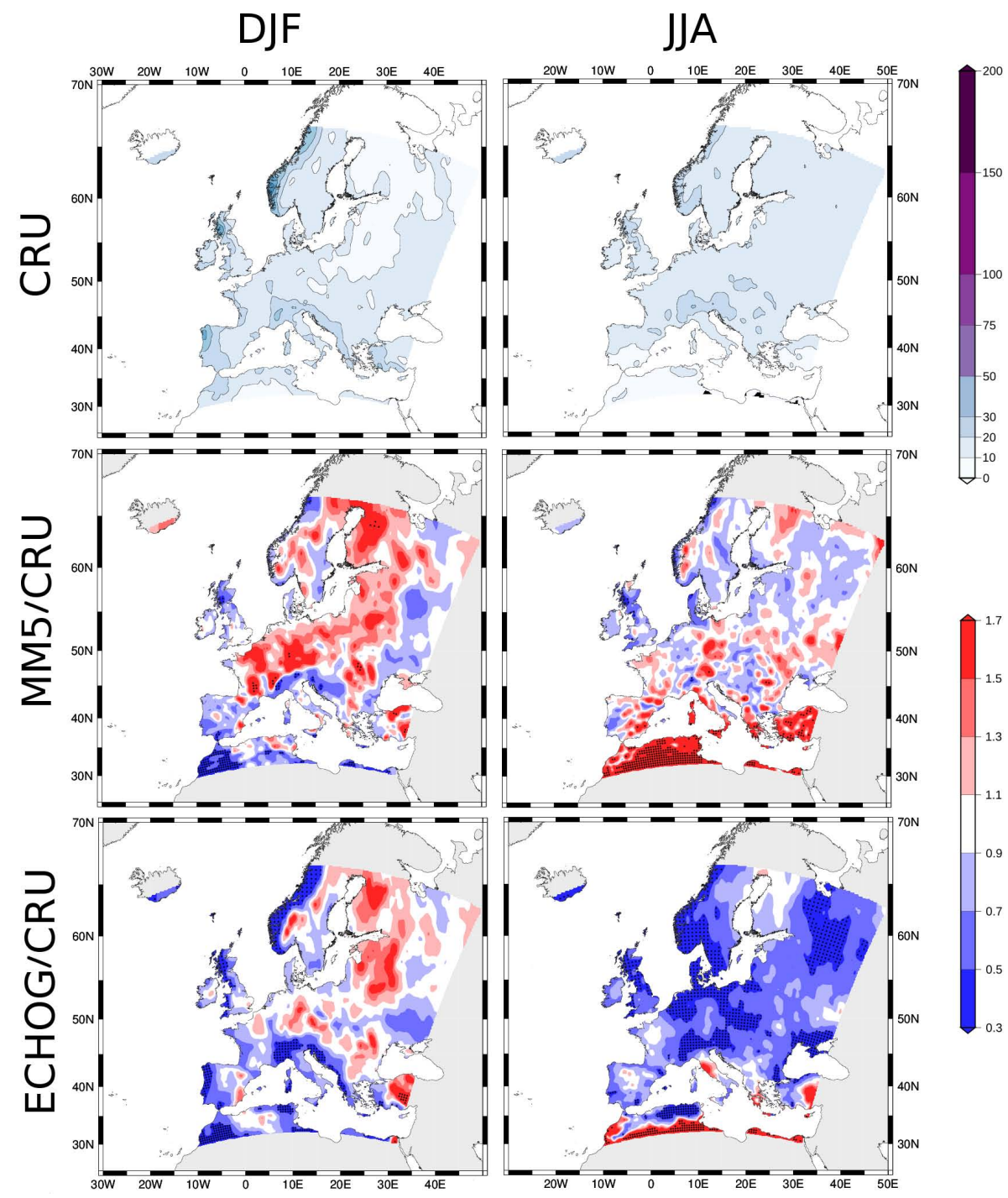

Fig. 7. Standard deviation of seasonal precipitation series (in $\mathrm{mm} \mathrm{month}^{-1}$ ) for the 1960-1990 period in winter (left panels) and summer (right panels) in CRU (top panels). Panels below show the ratio between MM5 driven by ECHO-G and CRU (middle panels) and ECHO-G alone and CRU (bottom panels). To perform the calculations, all datasets are spatially interpolated onto the MM5 grid, and only non-ocean grid cells are considered. The significance of the differences are tested through a two-tailed $T$ test at the $95 \%$ confidence level and it is indicated with small black circles in the figure.

regional models are small. This lack of added value is explained by the flat orography of these regions, which renders the use of high-resolution simulations less important. Finally, it is important to note that in some areas the bias in the regional simulation increases, as in Turkey or eastern Europe in summer. There is, however, no satisfactory explanation for this unexpected behaviour. One aspect where the RCM more clearly demonstrates its added value with respect to the coarse-resolution GCM is its capability to reproduce the shapes of the observed PDFs. In areas of complex topography, like the Iberian Peninsula or the Alps, the GCM is not capable of reproducing a realistic PDF (bimodal in the first case and especially flat and skewed in the second), but the RCM, although with a spatially averaged value tightly driven by the GCM, is able to reproduce the main features of these characteristic PDFs. However, it is worth noting that the shape of these PDFs is not determined by the local variability, but by the spatial variability of temperature within each region. Thus, the bimodality in the Iberian Peninsula in summer, for instance, is not due to the interannual variability, but to a bipolar behaviour of mean temperature in different parts of this area. This is apparent when considering temperature deviations from the long-term mean. When PDFs are calculated from these anomalies series (figures not shown for the sake of brevity) they do not show bimodality or skewness, 


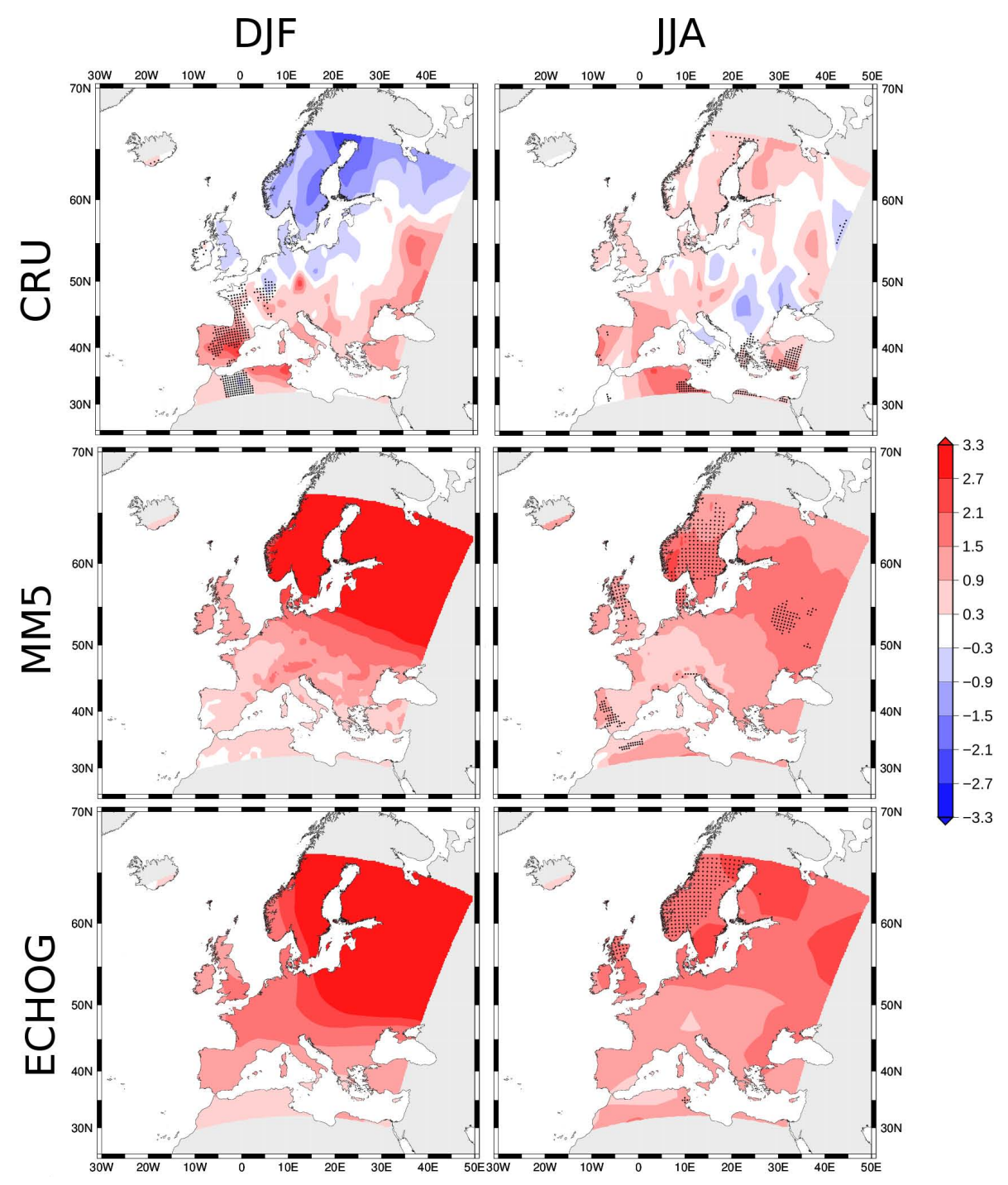

Fig. 8. Trends (in K century ${ }^{-1}$ ) in the seasonal SAT series in the 1900-1990 period for winter (left panels) and summer (right panels) in CRU (top panels) MM5 driven by ECHO-G (middle panels), and ECHO-G alone (bottom panels). To perform the calculations, all datasets are spatially interpolated onto the MM5 grid, and only non-ocean grid cells are considered. The significance of the trends is tested through the Mann-Kendall test, and it is indicated with small black circles in the figure.

and the range of the PDF generated by both models match very well the observations.

Figure 11 represents the PDFs for the seasonal precipitation in the same nine areas as before. In winter, the overestimation of zonal circulation prompts ECHO-G to overestimate precipitation regimes relative to the observations. The RCM is able to partly correct these biases, reducing the overestimation of precipitation and narrowing differences with the observations, specially in areas of complex topography such as Turkey, the Alps or the Iberian Peninsula. However, in areas where precipitation is strongly dominated by the zonal flow, such as Scandinavia, or where the higher resolution of the RCM does not result in a large difference due to their flat orography, like eastern and central Europe, MM5 develops a similar climatology as the driving model, leading to an overestimation of precipitation also in the regional model. In summer, both models reproduce the strong skewness of precipitation PDF over dry areas, such as Turkey, The Balkans or the Iberian Peninsula, although the RCM displays a better performance in seasons with mean precipitation below $20 \mathrm{~mm} \mathrm{month}^{-1}$. In the rest of the areas, the MM5 climatology is closer to observations, more noticeably in the right tail of the distribution, where ECHO-G underestimates precipitation. As before, in central Europe there is no clear gain from the high-resolution simulation. 


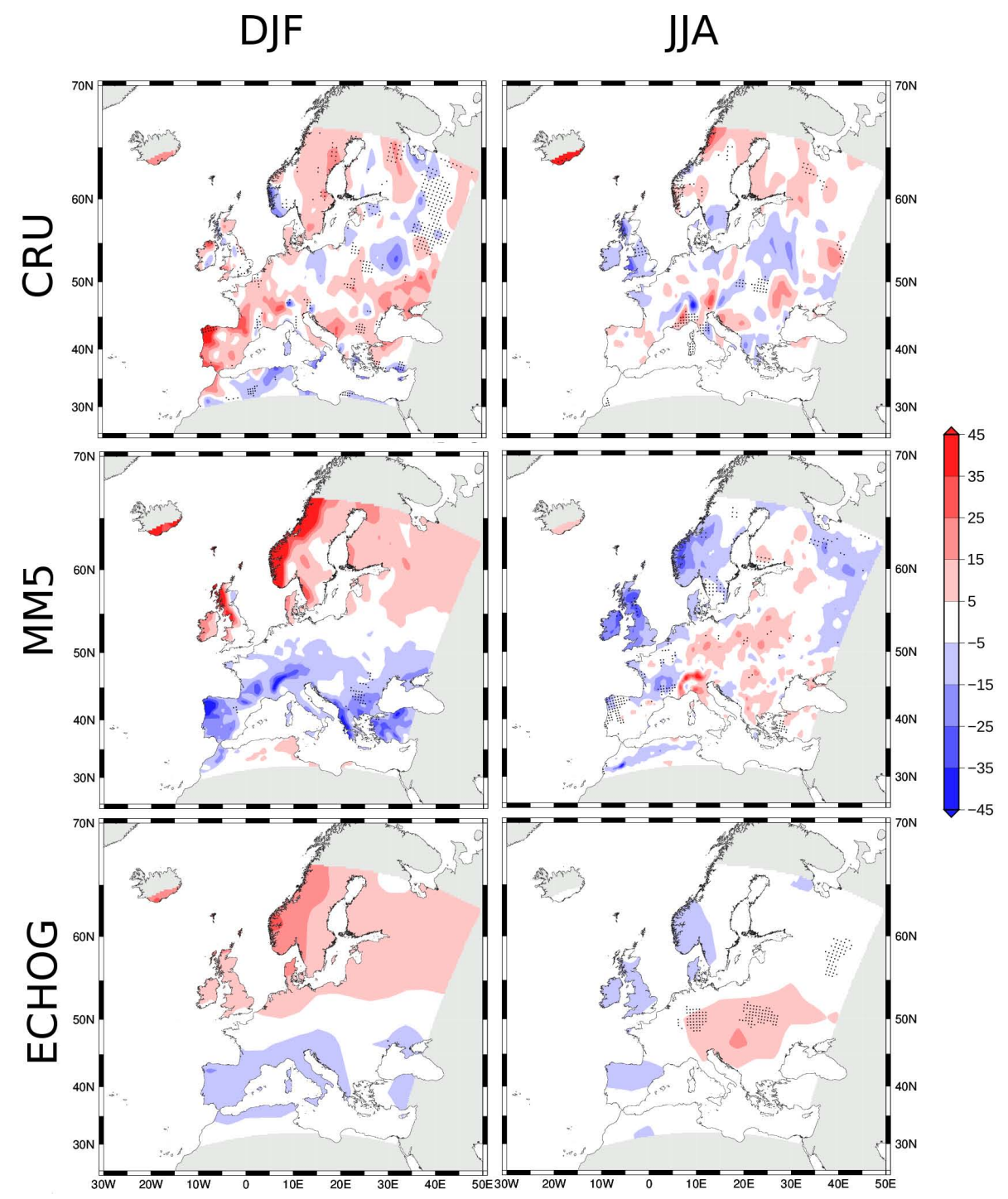

Fig. 9. Trends (in mm month ${ }^{-1}$ century $^{-1}$ ) in the seasonal precipitation series in the 1900-1990 period for winter (left panels) and summer (right panels) in CRU (top panels) MM5 driven by ECHO-G (middle panels), and ECHO-G alone (bottom panels). To perform the calculations, all datasets are spatially interpolated onto the MM5 grid, and only non-ocean grid cells are considered. The significance of the trends is tested through the Mann-Kendall test, and it is indicated with small black circles in the figure.

\section{Evolution of PDFs through the simulation}

All climate change projections with state-of-the-art climate models produce a warming trend during the 21 st century, and in some of them the warming trend is accompanied by an intensification of different types of extreme episodes (Christensen et al., 2007). Particularly for the same model setup employed here, Gómez-Navarro et al. (2010) found such widening of SAT distribution over the Iberian Peninsula under warming scenarios. Thus, a relevant question that is addressed with this simulation is whether changes in the probability distribution can be also identified in a palaeoclimate context. This is, whether the climate becomes more or less spatially heterogeneous in different periods as a function of the external forcing.

With this purpose, we calculate the PDFs of the seasonal series of SAT and precipitation in significantly different periods to analyse their changes over time. We select a reference period in the last part of the simulation when the anthropogenic forcing is more noticeable (1950-1990) and two cold periods: the Late Maunder Minimum (1675-1715) and the Dalton Minimum (1790-1830), characterized by reduced solar activity and the occurrence of important volcanic events, respectively, as illustrated by Fig. 1. PDFs are calculated separately for the nine areas shown in Fig. 2, and with the same methodology as described in the former section. Differences in the resulting PDFs for different periods 


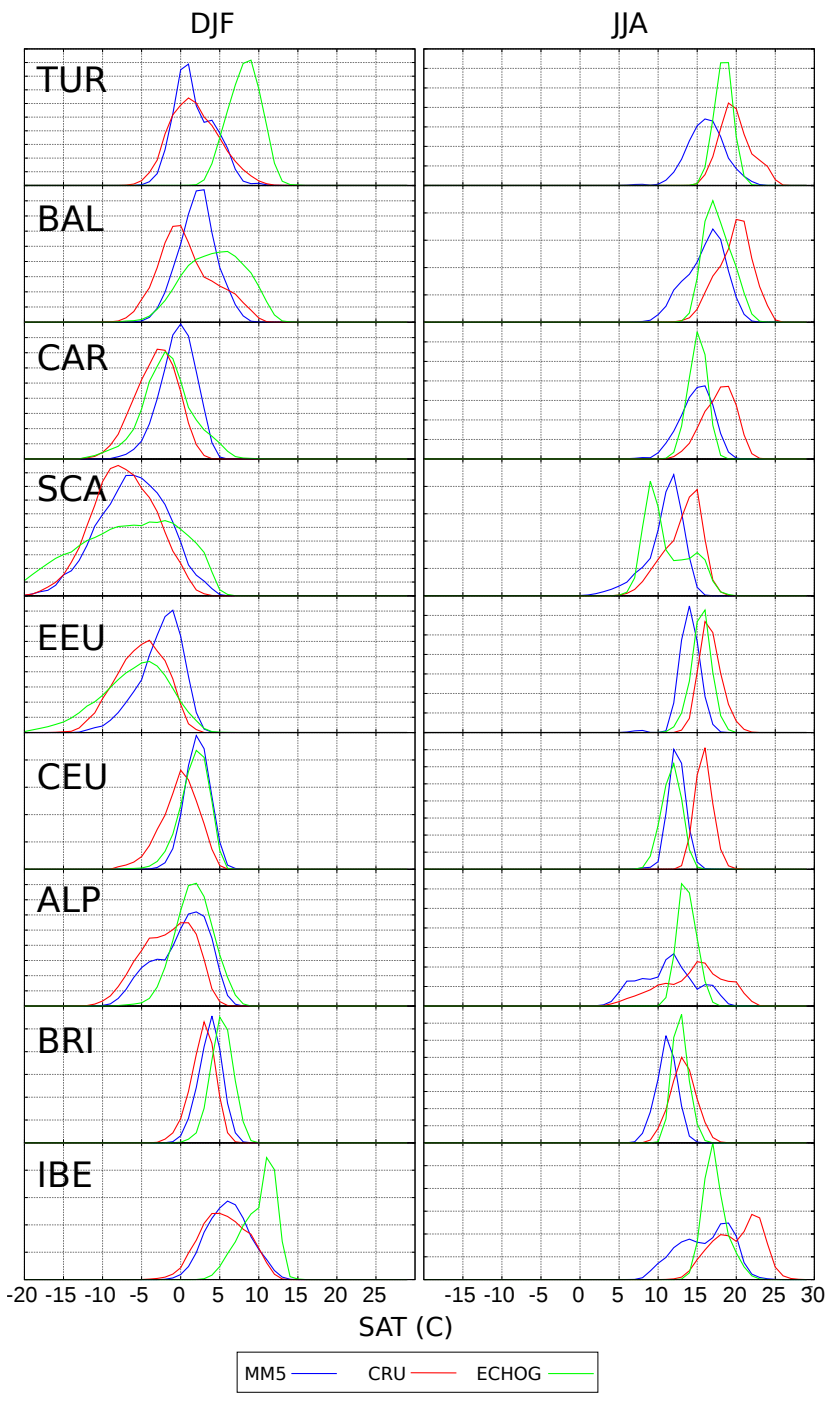

Fig. 10. PDFs of seasonal series of SAT in the nine sub-areas of Europe shown in Fig. 2. The results for winter (left panels) and summer (right panels) are presented for MM5, CRU and ECHOG. The horizontal axis shows the units of SAT in Celsius degree, while the vertical indicates relative frequency in arbitrary units.

(not shown here for the sake of brevity) are tested with the Kolmogórof-Smirnov test. The results demonstrate that despite an obvious shift in the mean, the PDFs do not significantly change their structure or amplitude, and present, for both cold periods analysed, the same shapes depicted in Figs. 10 and 11 for each area.

Generalizing this, we further analyse whether the spatial gradients remain constant through the simulation by calculating the evolution of the quantiles of the spatial distribution of SAT and precipitation within each sub-region of Fig. 2. The results are shown in Figs. 12 and 13 for SAT and precipitation, respectively. Shading represents the evolution of several quantiles of the spatial distribution of each variable in a different sub-area, while the black line represents the median of

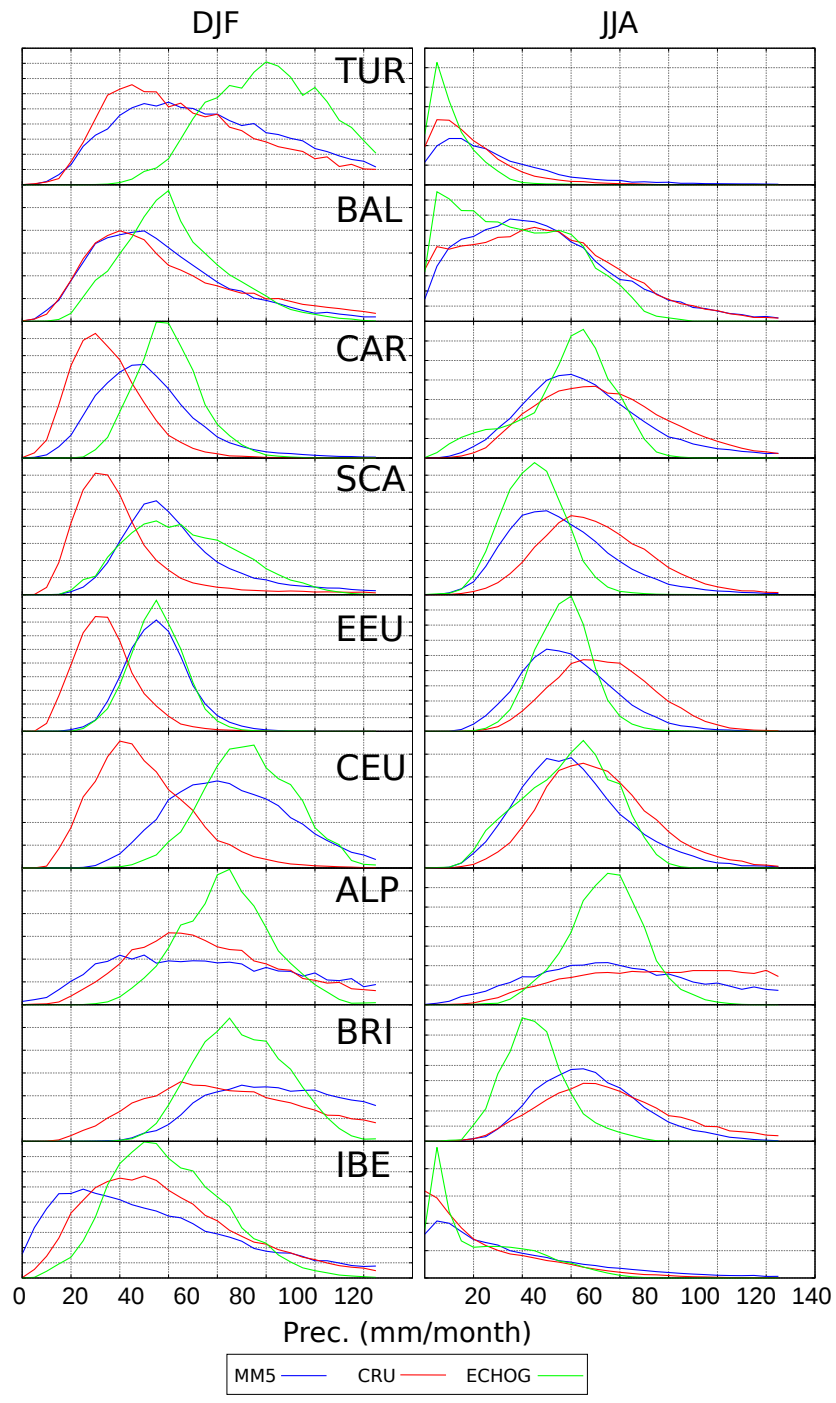

Fig. 11. PDFs of seasonal series of precipitation in the nine subareas of Europe shown in Fig. 2. The results for winter (left panels) and summer (right panels) are presented for MM5, CRU and ECHO-G. The horizontal axis shows the units of precipitation in mm month ${ }^{-1}$, while the vertical indicates relative frequency in arbitrary units.

this distribution. These quantiles are calculated at annual basis, and separately for winter and summer. Finally, the series are smoothed through a Hamming window of 30 time steps to facilitate the visualization.

Regarding temperature, the first aspect to note is that there are areas where the spatial gradient is particularly intense (note that every graph has a different vertical scale), and thus in these areas the gain obtained from the use of the RCM is specially noticeable. The Alps for example, being the smallest area of those considered here, is the one that shows larger span, with a range between the 10 and 90 percentiles up to $8^{\circ} \mathrm{C}$ in winter and $10^{\circ} \mathrm{C}$ in summer. Scandinavia also presents a large heterogeneity, related with the 


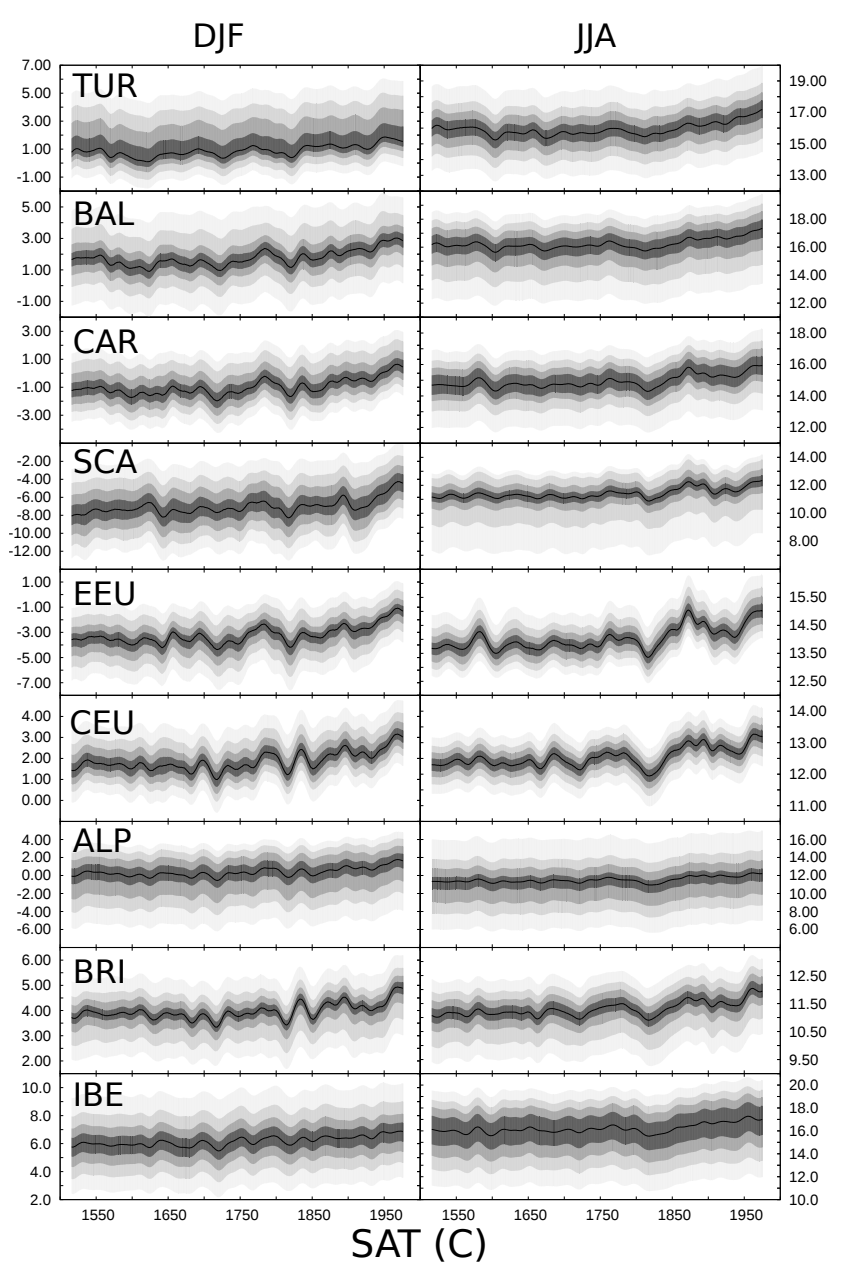

Fig. 12. Temporal series of SAT quantiles in the nine areas considered in Fig. 2. The filled curves with different grey shading encompass the percentiles between 10 and 90 of the SAT field in each time step, while the solid line represents the median. The series are smoothed through a Hamming window of 30 time steps to emphasise the low-frequency variability and facilitate the visualization.

strong north-south gradient of temperatures, although in this case the variability is larger in winter than in summer $\left(10^{\circ} \mathrm{C}\right.$ versus $7^{\circ} \mathrm{C}$ ). These two areas are also those where the climate variability is more intense, with differences in the median between the coldest and the warmest periods up to 3.5 and $2.5^{\circ} \mathrm{C}$ in winter for Scandinavia and the Alps, respectively. In contrast, central Europe is one of the areas where the added value of the higher model resolution is less noticeable, with spreads between the 10 and 90 percentiles smaller than 4 and $3{ }^{\circ} \mathrm{C}$ for winter and summer, respectively, and differences in the median between the warmest and coldest period of about $1.4^{\circ} \mathrm{C}$ in both seasons. In every area the MM5ECHO-G setup simulates the clear tendency toward warming in the last part of the simulation. It is preceded by a strong cold period around 1810, coincidental with an increase in the number of volcanic events and lower solar activity (Dalton

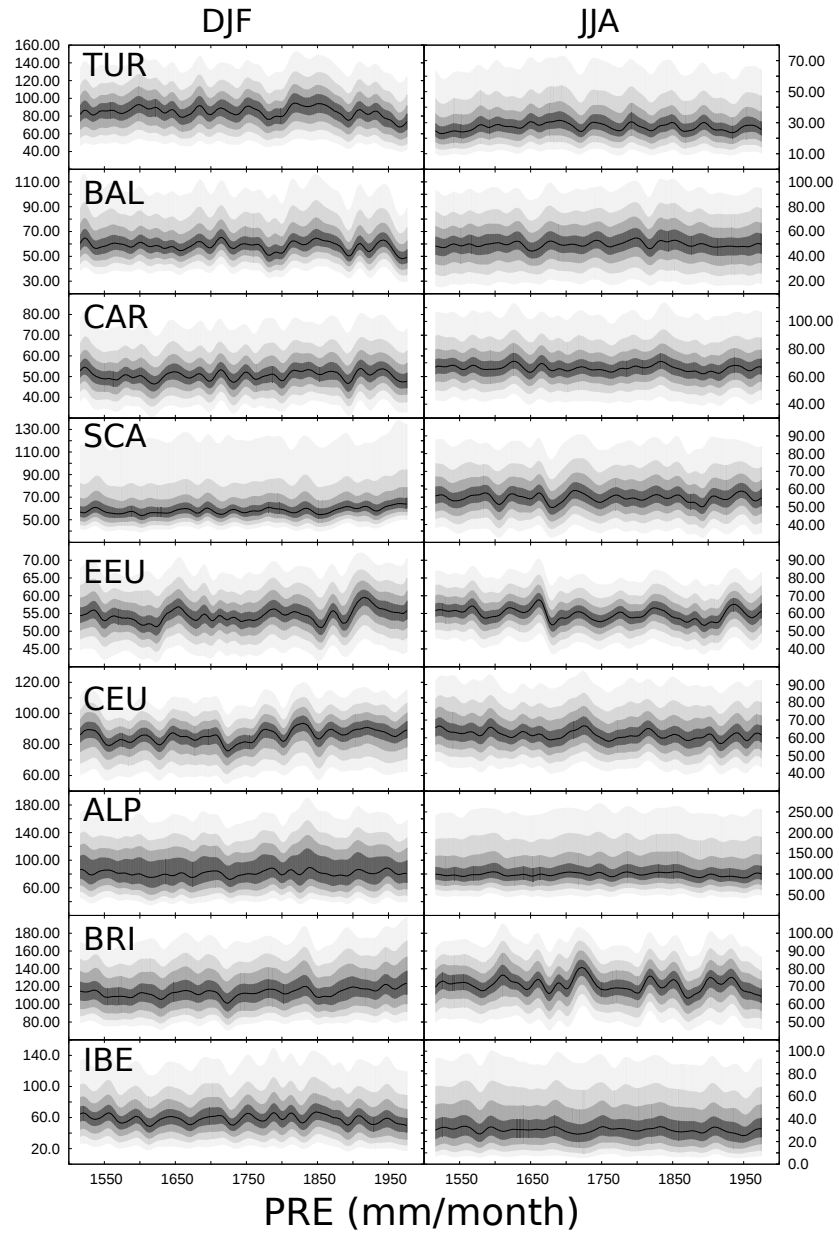

Fig. 13. Temporal series of precipitation quantiles in the nine areas considered in Fig. 2. The filled curves with different grey shading encompass the percentiles between 10 and 90 of the precipitation field in each time step, while the solid line represents the median. The series are smoothed through a Hamming window of 30 time steps to emphasise the low-frequency variability and facilitate the visualization.

Minimum), which is especially noticeable in the summer series. However, the Late Maunder Minimum (1675-1715), also a period with reduced solar activity, is hardly noticeable in the temperature series and is rather embedded in the longer cold period generally denominated as the Little Ice Age. Regarding the question of whether the spatial heterogeneity responds to external forcing, the simulation seems to indicate that this is not the case. As in the case of the PDFs of the series around cold periods discussed above, the spatial temperature range does not seem to be modulated by the shift of the mean values.

Figure 13 depicts the same information for precipitation. Many of the conclusions derived for temperature can be extended to this variable as well. Despite variations in the mean state in different periods, the spatial gradients are very similar in different periods, retaining a rather constant spread 
along the simulation. However, the probability distribution of this variable presents a strong positive skewness (which can be appreciated in the asymmetry of the percentiles), which makes the tails of the distribution behave asymmetrically in some areas where the changes in the mean value are most intense. This is apparent, for instance, in the asymmetric behaviour of the percentile trends in the distribution of winter precipitation in Scandinavia or The British Isles, where a large trend dominates the precipitation variability. The opposite behaviour is also found when the trend is negative, like in winter precipitation in the Balkans or summer precipitation in the British Isles. Unlike SAT, there is not a clear agreement in precipitation trends in the final simulated period, when the influence of anthropogenic forcings is more intense. Winter precipitation shows a clear negative trend in areas such as Turkey, the Balkans or the Iberian Peninsula, whereas it is positive in the British Isles and Scandinavia. Similarly, summer trends are heterogeneous and show no agreement among different areas (as already illustrated by Fig. 9), which is a indication of the strong dependence of this variable on the regional features of each area. In general, the signal of the forcings is not apparent in these series, and even the Dalton Minimum, which is clearly recognized in the SAT series, is not noticeable here by a coherent signal of increase or decrease of precipitation regimes. This different behaviour, weakly modulated by the external forcings, is due to the nature of this variable, strongly driven by internal variability at regional scales, as pointed out by Gómez-Navarro et al. (2012) in regional palaeosimulations for the Iberian Peninsula.

\section{Summary and conclusions}

In this study we illustrate the added value of a high-resolution climate simulation over Europe for the period 1500-1990, focusing the analysis on winter and summer seasons. Using the observational dataset CRU as benchmark, the RCM is capable of generating a high-resolution realistic climatology for SAT and precipitation over most areas of Europe in the reference period 1960-1990. The configuration employed here has, however, some important biases which have to be considered when evaluating the reliability of the simulation. Two biases are striking: the amplitude of the annual cycle of temperatures is underestimated and there is an overestimation of precipitation in northern Europe. This deficiency seems to be related to the overestimation of the zonal circulation simulated by the driving global model, a feature which is shared by other state-of-the-art GCMs.

Still, the MM5-ECHO-G setup accurately reproduces the variability of the seasonal series, especially its spatial structure, with a clear north-south gradient in winter temperature and a strongly orography-modulated precipitation pattern. In general terms, the RCM tends to underestimate the
SAT variability, although part of this difference is attributed to the higher spatial resolution of the observational dataset.

The comparison of the simulated and observed trends for SAT and precipitation during the 1900-1990 period shows that the RCM tends to overestimate the warming trend, especially in northern areas in winter. In particular, it simulates a homogeneously positive trend, which is absent in the observations, showing instead a negative, although not statistically significant, trend in the north. There may be several reasons for this difference. On the one hand, the simulation does not include anthropogenic tropospheric aerosols as forcing. It is well known that an important anthropogenic factor has been the increase of tropospheric aerosols, whose net effect is believed to produce a net cooling (Andreae et al., 2005). A complementary explanation for these differences can be found in the simulation of the circulation in the North Atlantic area. ECHO-G simulates a strong trend in the NAO index under anthropogenic forcing, which is absent in the observations. This trend leads to a trend in the zonal flow in northern Europe, which is consistent with the positive trends of SAT and precipitation simulated over this area and with the negative trends in winter precipitation in southern $\mathrm{Eu}-$ rope. The relationship between the observed NAO trend and the external forcing is by no means clear. Although most models in the CMIP5 and CMIP3 ensemble simulate a positive NAO trend in the 21 st century, driven by increasing greenhouse gas forcing (Miller et al., 2006), the long-term behaviour of the NAO in the 20th century, with negative trend until 1975, positive thereafter until 1990, and negative until present does not suggest a strong effect of the external forcing at decadal and longer time scales, as recently demonstrated by Gómez-Navarro and Zorita (2013). The lack of agreement between observations and simulations in the 20th century could then be just due to the uncorrelated internal variability present in both.

We also compare the PDFs for SAT and precipitation during the 1900-1990 period in the GCM, the RCM and in the observations. The added value of the RCM stands out in this analysis. The global model presents important biases, which the RCM is partly capable of reducing, narrowing differences with the observations. More importantly, the RCM is able to reproduce the shape of PDFs, simulating its complex structure or even its bimodality in areas of complex topography, such as the Iberian Peninsula or the Alps. It is noteworthy however that in areas with less complex orography such as central and eastern Europe, the added value of the RCMs is less important, and the use of GCM data to compare with climate reconstructions is a reasonable option.

Finally, we investigate the changes of PDFs in different periods, finding that despite an overall shift, their statistical properties barely change along the simulations. In particular, the variance of the distributions is not significantly reduced around cold periods such as the Dalton Minimum. This seems to be in contradiction with findings in the context of climate change projections, where an increased the spread in 
the PDFs is also projected (Christensen et al., 2007). However, it has to be noted that the increase of the forcings in the future projections is much stronger than the amplitude of forcing changes implemented in this palaeoclimate simulation. In any case this is a model result which has to be contrasted with available climate field reconstructions. This represents yet another form of cross-validation of climate reconstructions and simulations, which takes full advantage of the high resolution of the RCM. However, this comparison will be performed in a follow-up paper.

Acknowledgements. This work was funded by the Spanish Ministry of Science and Technology (project SPECMORE-CGL200806558-C02-02/CLI). J. J. Gómez-Navarro thanks the funding from the PRIME2 project (priority program INTERDYNAMIK, German Research Foundation). Thanks to Elena Bustamante and Jürg Luterbacher for the stimulating discussions.

The service charges for this open access publication have been covered by a Research Centre of the Helmholtz Association.

Edited by: H. Goosse

\section{References}

Andreae, M. O., Jones, C. D., and Cox, P. M.: Strong present-day aerosol cooling implies a hot future, Nature, 435, 1187-1190, doi:10.1038/nature03671, 2005.

Casty, C., Raible, C. C., Stocker, T. F., Wanner, H., and Luterbacher, J.: A European pattern climatology 1766-2000, Clim. Dynam., 29, 791-805, doi:10.1007/s00382-007-0257-6, 2007.

Chen, F. and Dudhia, J.: Coupling an Advanced Land SurfaceHydrology Model with the Penn State-NCAR MM5 Modeling System, Part I: Model Implementation and Sensitivity, Mon. Weather Rev., 129, 569-585, 2001a.

Chen, F. and Dudhia, J.: Coupling an Advanced Land SurfaceHydrology Model with the Penn State-NCAR MM5 Modeling System, Part II: Preliminary Model Validation, Mon. Weather Rev., 129, 587-604, 2001b.

Christensen, J. H., Hewitson, B., Busuioc, A., Chen, A., Gao, X., Held, I., Jones, R., Kolli, R. K., Kwon, W.-T., Laprise, R., Rueda, V. M., Mearns, L., Menéndez, C. G., Räisänen, J., Rinke, A., Sarr, A., and Whetton, P.: Regional Climate Projections, in: Climate Change 2007: The Physical Science Basis. Contribution of Working Group I to the Fourth Assessment Report of the Intergovernmental Panel on Climate Change, Cambridge University Press, Cambridge, UK and New York, NY, USA, 2007.

Dudhia, J.: Numerical study of convection observed during the winter monsoon experiment using a mesoscale two-dimensional model, J. Atmos. Sci., 46, 3077-3107, 1989.

Dudhia, J.: A Nonhydrostatic Version of the Penn StateNCAR Mesoscale Model: Validation Tests and Simulation of an Atlantic Cyclone and Cold Front, Mon. Weather Rev., 121, 1493-1513, 1993.
Gómez-Navarro, J. J., Montávez, J. P., Jiménez-Guerrero, P., Jerez, S., Garcia-Valero, J. A., and González-Rouco, J. F.: Warming patterns in regional climate change projections over the Iberian Peninsula, Meteorol. Z., 19, 275-285, 2010.

Gómez-Navarro, J. J., Montávez, J. P., Jerez, S., Jiménez-Guerrero, P., Lorente-Plazas, R., González-Rouco, J. F., and Zorita, E.: A regional climate simulation over the Iberian Peninsula for the last millennium, Clim. Past, 7, 451-472, doi:10.5194/cp-7-451-2011, 2011.

Gómez-Navarro, J. J., Montávez, J. P., Jiménez-Guerrero, P., Jerez, S., Lorente-Plazas, R., González-Rouco, J. F., and Zorita, E.: Internal and external variability in regional simulations of the Iberian Peninsula climate over the last millennium, Clim. Past, 8, 25-36, doi:10.5194/cp-8-25-2012, 2012.

Gómez-Navarro, J. J. and Zorita, E.: Atmospheric annular modes in simulations over the past millennium: No long-term response to external forcing, Geophys. Res. Lett., 40, 3232-3236, doi:10.1002/grl.50628, 2013.

González-Rouco, J. F., Beltrami, H., Zorita, E., and Stevens, M. B.: Borehole climatology: a discussion based on contributions from climate modeling, Clim. Past, 5, 97-127, doi:10.5194/cp-5-972009, 2009.

Grell, G. A.: Prognostic evaluation of assumptions used by cumulus parameterizations, Mon. Weather Rev., 121, 764-787, 1993.

Grell, G. A., Dudhia, J., and Stauffer, D. R.: A description of the fifth-generation Penn State/NCAR Mesoscale Model (MM5), Tech. Rep. NCAR/TN-398+STR, National Center for Atmospheric Research, Boulder, Colorado, 1994.

Harris, I., Jones, P., Osborn, T., and Lister, D.: Updated high-resolution grids of monthly climatic observations - the CRU TS3.10 dataset, Int. J. Climatol., doi:10.1002/joc.3711, in press, 2013.

Hong, S. Y. and Pan, H. L.: Nonlocal boundary layer vertical diffusion in a medium-range forecast model, Mon. Weather Rev., 124, 2322-2339, 1996.

Jacob, D., Barring, L., Christensen, O. B., Christensen, J. H., de Castro, M., Deque, M., Giorgi, F., Hagemann, S., Lenderink, G., Rockel, B., Sanchez, E., Schaer, C., Seneviratne, S. I., Somot, S., van Ulden, A., and van den Hurk, B.: An intercomparison of regional climate models for Europe: model performance in present-day climate, Climatic Change, 81, 31-52, doi:10.1007/s10584-006-9213-4, 2007.

Jerez, S., Montávez, J. P., Gómez-Navarro, J. J., Jiménez-Guerrero, P., Jiménez, J. M., and González-Rouco, J. F.: Temperature sensitivity to the land-surface model in MM5 climate simulations over the Iberian Peninsula, Meteorol. Z., 19, 1-12, 2010.

Jerez, S., Montávez, J. P., Jiménez-Guerrero, P., Gómez-Navarro, J. J., Lorente-Plazas, R., and Zorita, E.: A multi-physics ensemble of present-day climate regional simulations over the Iberian Peninsula, Clim. Dynam., 40, 3023-3046, doi:10.1007/s00382012-1539-1, 2013.

Kalnay, E., Kanamitsu, M., Kistler, R., Collins, W., Deaven, D., Gandin, L., Iredell, M., Saha, S., White, G., Woollen, J., Zhu, Y., Leetmaa, A., and Reynolds, R.: The NCEP/NCAR 40-Year Reanalysis Project, B. Am. Meteorol. Soc., 77, 437-470, 1996.

Kanamitsu, M. and DeHann, L.: The added Value Index: A new metric to quantify the added value of regional models, J. Geophys. Res., 116, D11106, doi:10.1029/2011JD015597, 2011. 
Küttel, M., Xoplaki, E., Gallego, D., Luterbacher, J., GarcíaHerrera, R., Allan, R., Barriendos, M., Jones, P. D., Wheeler, D., and Wanner, H.: The importance of ship log data: reconstructing North Atlantic, European and Mediterranean sea level pressure fields back to 1750 , Clim. Dynam., 34, 1115-1128, doi:10.1007/s00382-009-0577-9, 2010.

Legutke, S. and Voss, R.: The Hamburg atmosphere-ocean coupled circulation model ECHO-G, Tech. rep., DKRZ, Hamburg, Germany, 1999.

Luterbacher, J., Dietrich, D., Xoplaki, E., Grosjean, M., and Wanner, H.: European seasonal and annual temperature variability, trends, and extremes since 1500, Science, 303, 1499-1503, 2004.

Miller, R. L., Schmidt, G. A., and Shindell, D. T.: Forced annular variations in the 20th century Intergovernmental Panel on Climate Change Fourth Assessment Report models, J. Geophys. Res., 111, 1-17, doi:10.1029/2005JD006323, 2006.

Mlawer, E. J., Taubman, S. J., Brown, P. D., Iacono, M. J., and Clough, S. A.: Radiative transfer for inhomogeneous atmospheres: RRTM, a validated correlated- model for the longwave, J. Geophys. Res., 102, 16663-16682, 1997.

Osborn, T. J. and Hulme, M.: Development of a Relationship between Station and Grid-Box Rainday Frequencies for Climate Model Evaluation, J. Climate, 10, 1885-1908, doi:10.1175/1520-0442(1997)010<1885:DOARBS > 2.0.CO;2, 1997.
Prömmel, K., Geyer, B., Jones, J. M., and Widmann, M.: Evaluation of the skill and added value of a reanalysis-driven regional simulation for Alpine temperature, Int. J. Climatol., 773, 760-773, doi:10.1002/joc.1916, 2009.

Schimanke, S., Meier, H. E. M., Kjellström, E., Strandberg, G., and Hordoir, R.: The climate in the Baltic Sea region during the last millennium simulated with a regional climate model, Clim. Past, 8, 1419-1433, doi:10.5194/cp-8-1419-2012, 2012.

Schmidt, G. A., Annan, J. D., Bartlein, P. J., Cook, B. I., Guilyardi, E., Hargreaves, J. C., Harrison, S. P., Kageyama, M., LeGrande, A. N., Konecky, B., Lovejoy, S., Mann, M. E., Masson-Delmotte, V., Risi, C., Thompson, D., Timmermann, A., Tremblay, L.B., and Yiou, P.: Using paleo-climate comparisons to constrain future projections in CMIP5, Clim. Past Discuss., 9, 775-835, doi:10.5194/cpd-9-775-2013, 2013.

Zorita, E., Von Storch, H., González-Rouco, J. F., Cubasch, U., Luterbacher, J., Legutke, S., Fischer-Bruns, I., and Schlese, U.: Climate evolution in the last five centuries simulated by an atmosphere-ocean model: global temperatures, the North Atlantic Oscillation and the Late Maunder Minimum, Meteorol. Z., 13, 271-289, doi:10.1127/0941-2948/2004/0013-0271, 2004. 